\title{
Análise hidráulica de um filtro rápido bifluxo em escala piloto de dupla camada filtrante com descarga de fundo intermediária para tratamento de água de abastecimento
}

\section{Hydraulic analysis of a biflow rapid filter in pilot scale with dual media bed and intermediate downflush for drinking water treatment}

Data de entrada: $11 / 07 / 2019$

Data de aprovação: 04/08/2020

Diego Brunelli Ghisi' ${ }^{1 *}$ | Fernando Hymnô de Souza' | Lorena Régis Vieira de Freitas ${ }^{1}$ |

Maurício Luiz Sens ${ }^{1}$

DOI: https://doi.org/10.36659/dae.2021.087

ORCID ID

Ghisi DB (D) https://orcid.org/0000-0002-7984-3590

Souza FH (D) https://orcid.org/0000-0002-4542-7695
Freitas LRV (1) https://orcid.org/0000-0003-1237-9735

Sens ML (iD https://orcid.org/0000-0001-5013-4267

\section{Resumo}

Filtros bifluxos foram utilizados historicamente empregando-se tubos de PVC com ranhuras para a coleta do filtrado, cujo entupimento recorrente limitou a aplicação dessa modalidade de filtração. Nesta pesquisa estudou-se um filtro rápido bifluxo acrescentando-se outras tecnologias atuais, como dupla camada filtrante, descarga de fundo com injeção na interface e coleta do filtrado por bocais desmontáveis. O sistema de tratamento foi a filtração direta, com taxa de filtração constante e igual a $400 \mathrm{~m}^{3} / \mathrm{m}^{2}$.d. Verificou-se uma baixa ação de profundidade, indicando que o leito poderia ser reduzido ou ter sua granulometria alterada. A duração média das carreiras de filtração foi de 3,0 h; a produção efetiva foi de $73 \%$, com turbidez média de 0,9 uT da água filtrada. O bocal sofreu colmatação ao longo do estudo, tendo sido necessários cerca de 3 minutos para sua desobstrução.

Palavras-chave: Tratamento de água. Filtração rápida. Filtração direta. Filtração bifluxo. Filtro bifluxo.

\section{Abstract}

Biflow filters were used historically using slotted PVC tubes to collect the filtrate, whose recurrent clogging limited the application of this filtration modality. In this research a biflow rapid filter was studied, adding some current technologies, such as dual-media bed, intermediate downflush and the use of detachable nozzles to collect the filtrate. The treatment system was direct filtration, with a constant filtration rate of $400 \mathrm{~m}^{3} / \mathrm{m}^{2} . d$. It was observed a low depth action, indicating that the filter bed could be reduced or its granulometry altered. The average duration of filtration runs was $3.0 \mathrm{~h}$, leading to a liquid production of $73 \%$, with a mean turbidity of 0.9 UT of the filtered water. The nozzle was clogged throughout the study, taking about 3 minutes for its clearance. Keywords: Water treament. Rapid filtration. Direct filtration. Biflow filtration. Biflow filter.

\footnotetext{
${ }^{1}$ Universidade Federal de Santa Catarina - Florianópolis - Santa Catarina - Brasil.

* Autor correspondente: diego_satcahotmail.com.
} 


\section{INTRODUÇÃO}

Os principais aspectos para avaliar a performance de um filtro no tratamento de água são: a qualidade do filtrado, a duração da carreira de filtração e a produção efetiva.

Um aspecto que está diretamente relacionado à avalição quali e quantitativa da filtração é a ação de profundidade, que, segundo Di Bernardo e Dantas (2005), expressa-se como consequência de uma sucessão de estágios com relação à colmatação das subcamadas que formam o leito filtrante. Preferencialmente, o processo de filtração rápida deve ocorrer por ação de profundidade, o que tende a favorecer uma maior produção efetiva de água (DI BERNARDO et al., 2017).

A produção efetiva consiste na razão entre a quantidade de água filtrada que é encaminhada ao processo subsequente na ETA e o total de água que passa pelo filtro. A produção efetiva é avaliada usando o conceito de unidade de volume de carreira de filtração (UVCF) e unidade de volume da retrolavagem (UVR) (TRUSSELL et al., 1999). Considera-se ainda a unidade de volume descartada durante a recuperação, ou amadurecimento do filtro (UVRec). A UVCF é o volume de água que passa através do filtro durante a carreira; a UVR é o volume necessário para a retrolavagem do filtro e UVRec é o volume utilizado no período de recuperação. A razão entre a quantidade de água líquida e total filtrada é a produção efetiva (PE), conforme Eq. 1 a seguir:

$$
P E=\frac{U V C F-U V R-U V R e C}{U V C F}
$$

CRITTENDEN et al. (2011) citam que projetos de filtros podem ser executados para se obter uma produção efetiva de $95 \%$, mas para isso é necessário que a UVCF alcance ao menos $200 \mathrm{~m}^{3} / \mathrm{m}^{2}$.
Entre as modalidades de filtros mais empregadas está o filtro rápido ascendente, em que a água a ser tratada passa primeiramente por grãos maiores do leito filtrante, que vão diminuindo ao longo do caminho que ela percorre (DI BERNARDO, 2003).

No caso da filtração ascendente, o processo de filtração inicia na camada de pedregulho, onde há formação intensa de flocos, tornando-se fundamental a execução de descarga de fundo intermediária antes da lavagem do filtro. Essa técnica consiste em interromper por curto intervalo de tempo a carreira do filtro e realizar uma descarga de fundo, e pode ser executada de diferentes maneiras. Com esse procedimento fazse uma limpeza parcial do filtro, removendo o material retido basicamente na camada suporte e em alguns centímetros da camada de areia próxima ao pedregulho (DI BERNARDO, 2003). Di Bernardo et al. (1987) estudaram diferentes formas de realização das descargas de fundo intermediárias, concluindo como a mais eficiente em termos de turbidez e coliformes totais a que se utiliza água de fonte externa para introdução na interface, com manutenção do nível de água no filtro praticamente constante.

Segundo Richter e Azevedo Netto (1991), um problema descrito com certa frequência quanto ao uso dos filtros ascendentes é a fluidificação do leito filtrante, permitindo que flocos anteriormente depositados sejam liberados junto ao efluente. Nesse aspecto, tem-se buscado alternativas para aprimorar resultados no uso desses filtros. Uma das soluções foi proposta na antiga União das Repúblicas Socialistas Soviéticas (URSS), sendo o sistema A.K.X., em que uma parcela da vazão é aplicada acima da camada filtrante, e a água clarificada é drenada no interior dessa camada, abaixo da superfície. Tal variedade de filtro é também chamada de filtro bifluxo. 
O filtro bifluxo tem como vantagens a maior vazão de água filtrada, o controle da expansão do meio filtrante, a economia nos custos de implantação e o menor consumo relativo de água de lavagem. Um problema relativamente comum em sua operação é o entupimento da canalização de coleta da água filtrada, realizado geralmente via tubos de PVC com ranhuras.

No filtro bifluxo, a lavagem do filtro pode ocorrer de modo convencional, utilizando fluxo ascendente (MACINTYRE, 1991). Hamann e Mckinney (1968) especificaram alguns critérios de projeto dos filtros bifluxo empregados na antiga URSS à época: leito composto por areia contendo uma profundidade entre $1,50 \mathrm{~m}$ e $1,65 \mathrm{~m}$, taxa de filtração do fluxo descendente de 120 a $150 \mathrm{~m}^{3} /$ $\mathrm{m}^{2}$.d e taxa de filtração do fluxo ascendente 180 a $210 \mathrm{~m}^{3} / \mathrm{m}^{2}$.d. Os autores ainda citam o sistema de coleta do filtrado composto por tubos de plástico vinílico com fendas e locado 0,45 a 0,60 m abaixo do limite superior da areia, além da operação de retrolavagem ocorrer com água em fluxo ascendente a uma taxa de 47,5 a $55 \mathrm{~m}^{3} / \mathrm{m}^{2} . \mathrm{h}$ por 5 a 6 min.

Vignesan et al. (1983) também destacam alguns critérios de projeto: leito filtrante geralmente composto apenas por areia, com tamanho efetivo de 0,90 a $1,20 \mathrm{~mm}$ e com profundidade total de 1,50 a 1,70 m. É recomendado o emprego de dupla camada filtrante, composta por areia e antracito. Mesmas faixas de taxa de filtração citadas no parágrafo anterior, mas a taxa total podendo ser elevada a até $480 \mathrm{~m}^{3} / \mathrm{m}^{2}$.d, se utilizada dupla camada filtrante.

Diante da carência de estudos sobre filtros bifluxos, foi realizada uma análise das potencialidades e pontos fracos desse tipo de filtro. Este trabalho avaliou uma unidade em escala piloto composta por critérios de projeto selecionados, entre o uso de bocais desmontáveis para a coleta da água filtrada.

\section{MATERIAIS E MÉTODOS}

Projetou-se e executou-se em escala piloto um filtro rápido bifluxo de dupla camada (antracito e areia) com emprego de descarga de fundo intermediária. O local foi o Laboratório de Potabilização de Águas (LAPOÁ), em sua unidade anexa à Estação de Tratamento de Água da Lagoa do Peri, estando esta última sob responsabilidade da Companhia Catarinense de Águas e Saneamento (CASAN). A água bruta passou pelo processo de mistura rápida (coagulação) com uma dosagem de $15 \mathrm{mg} / \mathrm{L}$ de hidroxicloreto de alumínio (PAC) com teor mínimo de $\mathrm{Al} 2 \mathrm{O} 3$ de $10,5 \%$ de imediatamente antes de ser filtrada, isto é, o filtro compôs um sistema de filtração direta. Foram consideradas para análise dos resultados 10 carreiras de filtração.

A água do manancial Lagoa do Peri é utilizada para o abastecimento de parte da população do sul e do leste desta ilha, após tratamento por meio de filtração direta descendente. A ETA da Lagoa do Peri foi projetada com o uso da tecnologia de filtração direta descendente com dupla camada de antracito e areia. Essa concepção, de acordo com DALSASSO \& SENS (2006), é compatível com os parâmetros de turbidez e cor verdadeira do manancial, em geral inferiores a $10 \mathrm{uT}$ e $20 \mathrm{uH}$, respectivamente. Entretanto, após cerca de um ano de operação da ETA, observou-se a elevação da concentração de fitoplâncton na Lagoa do Peri, passando de cerca de $10.000 \mathrm{ind} / \mathrm{mL}$ para ocorrências que chegavam a $250.000 \mathrm{ind} / \mathrm{mL}$. As espécies dominantes de fitoplâncton desse manancial são as cianobactérias Cylindrospermopsis raciborskii e Pseudanabaena galeata, havendo ainda a presença da diatomácea Aulacoseira ambígua, sendo todos esses microrganismos filamensos (DE SOUZA; MONDARDO; SENS; 2017), o que faz com que a penetração, ou filtração em profundidade, seja baixa, e as carreiras sejam mais curtas ( $\mathrm{SCHÖN-}$ TAG, 2015; MONDARDO, 2004). Apesar de a 
água bruta conter características que a tornam inapropriada para a aplicação de filtração direta, a mesma proporcionou uma celeridade das carreiras de filtração, obtendo-se, assim, resultados mais rápidos para o estudo.

O filtro piloto foi executado em um segmento de tubo de policloreto de vinila (PVC) de $250 \mathrm{~mm}$ de diâmetro e com 4,9 m de altura. A câmara de carga para a parcela de fluxo ascendente do filtro, fixada lateralmente ao filtro, consistiu em um segmento de tubo de PVC de $75 \mathrm{~mm}$ de diâmetro e com 5,80 m de altura. A carga hidráulica para a parcela do filtro de fluxo descendente foi composta pelo seu próprio sobrenadante. 0 leito filtrante foi constituído como consta na Tabela 1:

Tabela 1 - Características da camada filtrante.

\begin{tabular}{|c|c|c|}
\hline \multicolumn{2}{|c|}{ Parâmetro } & Valor/Descrição \\
\hline \multirow{6}{*}{$\begin{array}{l}\text { Parte superior do filtro } \\
\text { (fluxo descendente) }\end{array}$} & $\begin{array}{l}\text { Espessura da camada } \\
\text { de antracito }\end{array}$ & $0,60 \mathrm{~m}$ \\
\hline & $\begin{array}{c}\text { Tamanho efetivo do } \\
\text { antracito }\end{array}$ & $0,90 \mathrm{~mm}$ \\
\hline & $\begin{array}{l}\text { Coeficiente de } \\
\text { uniformidade do } \\
\text { antracito }\end{array}$ & 1,5 \\
\hline & $\begin{array}{c}\text { Espessura da camada } \\
\text { de areia }\end{array}$ & $0,25 \mathrm{~m}$ \\
\hline & $\begin{array}{c}\text { Tamanho efetivo da } \\
\text { areia }\end{array}$ & $0,50 \mathrm{~mm}$ \\
\hline & $\begin{array}{c}\text { Coeficiente de } \\
\text { uniformidade da areia }\end{array}$ & 1,5 \\
\hline \multirow{5}{*}{$\begin{array}{l}\text { Parte inferior do filtro } \\
\text { (fluxo ascendente) }\end{array}$} & $\begin{array}{c}\text { Espessura da camada } \\
\text { de areia }\end{array}$ & $1,70 \mathrm{~m}$ \\
\hline & $\begin{array}{l}\text { Tamanho efetivo da } \\
\text { areia usada nos } 0,30 \\
\text { m superiores }\end{array}$ & $0,51 \mathrm{~mm}$ \\
\hline & $\begin{array}{l}\text { Coeficiente de } \\
\text { uniformidade da areia } \\
\text { usada nos } 0,30 \mathrm{~m} \\
\text { superiores }\end{array}$ & 1,47 \\
\hline & $\begin{array}{c}\text { Tamanho efetivo da } \\
\text { areia usada nos } 1,40 \\
\text { m inferiores }\end{array}$ & $0,58 \mathrm{~mm}$ \\
\hline & $\begin{array}{l}\text { Coeficiente de } \\
\text { uniformidade da areia } \\
\text { usada nos } 1,40 \mathrm{~m} \\
\text { inferiores }\end{array}$ & 1,74 \\
\hline
\end{tabular}

A camada suporte contou com uma profundidade total de $30 \mathrm{~cm}$, com seus grãos menores no centro, possibilitando inclusive a lavagem com ar e água. Sua configuração consta na Tabela 2:
Tabela 2 - Configuração da camada suporte do filtro bifluxo.

\begin{tabular}{|c|c|c|}
\hline Subcamada & $\begin{array}{c}\text { Tamanho dos grãos } \\
(\mathbf{m m})\end{array}$ & Espessura (cm) \\
\hline 1 & $12,7-25,4$ & 5 \\
\hline 2 & $6,4-12,7$ & 5 \\
\hline 3 & $3,2-6,4$ & 10 \\
\hline 4 & $6,4-12,7$ & 5 \\
\hline 5 & $12,7-25,4$ & 5 \\
\hline
\end{tabular}

Adotou-se o método de descarga de fundo concomitantemente à introdução de água na interface, sendo essa etapa executada com a manutenção do nível de água no filtro constante. A alimentação com água foi proveniente de fonte externa, no caso, o mesmo reservatório de água filtrada utilizada para a retrolavagem. A injeção de água na interface foi executada sob uma taxa de $1220 \mathrm{~m}^{3} / \mathrm{m}^{2}$.d, ou $51 \mathrm{~m}^{3} / \mathrm{m}^{2}$.h.

A descarga de fundo com injeção na interface foi realizada sempre que a colmatação ocorreu primeiramente na parcela do filtro que opera no fluxo ascendente, durante o andamento da carreira de filtração, e também ao fim dessa última, previamente à retrolavagem do filtro. A duração dessa operação foi fixada em $25 \mathrm{~s}$, sendo que, com esse tempo e taxa especificados, cada operação consumiu um volume aproximado de $20 \mathrm{~L}$.

Quanto à drenagem da água filtrada, buscouse uma alternativa para a coleta do filtrado que potencialmente evite problemas de obstrução e que, caso isso ocorra, haja um meio viável de promover sua desobstrução. Adotou-se, então, a utilização de um item empregado geralmente no fundo de filtros de fluxo descendente, qual seja, o bocal desmontável. Tais bocais, também chamados de crepinas, por terem um uso no tratamento de água que envolve seu contato direto com material filtrante (areia, em geral), possuem potencialmente menores chances de sofrer obstrução e forçar a interrupção da carreira de filtros bifluxos. A Fig. 1 ilustra o bocal descrito na sua forma encaixada e com suas peças separadas: 

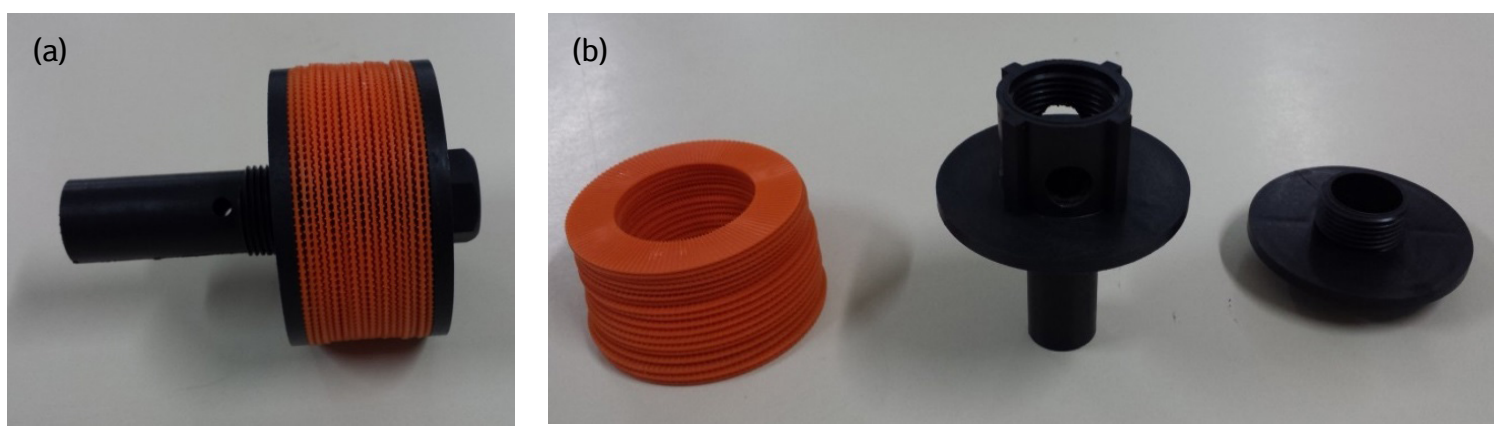

Figura 1 - a) Bocal desmontável em sua forma encaixada; b) bocal em sua forma desmontada. Fonte: $\mathrm{O}$ autor.

Os bocais propostos possuem corpo composto por nylon e fibra de vidro, que suporta e fixa discos em polipropileno, os quais possuem sulcos uniformes com direção radial em relação à peça. Os sulcos por onde o filtrado adentra ao corpo da crepina possuem aberturas com dimensões menores que $0,40 \mathrm{~mm}$ (HIDRO SOLO, 2019), valor abaixo do tamanho efetivo dos materiais filtrantes geralmente empregados, inclusive da areia empregada nesse projeto $(0,50$ e 0,60 mm). Esse fato reduz as possibilidades de colmatação da peça. Ainda, diferentemente de outros bocais, os desse tipo são desmontáveis, sendo facilmente desencaixados e permitindo uma rápida limpeza e retorno à operação. Suas partes inferior e superior são rosqueáveis, ambas mantendo os discos comprimidos e encaixados na sua porção intermediária. O diâmetro externo dos discos é de $80 \mathrm{~mm}$

No presente estudo, o bocal descrito foi conectado a um segmento de mangueira corrugada de PVC com diâmetro de $25 \mathrm{~mm}$. Adotou-se tal material visto que a mangueira deveria, além de não dobrar, ter flexibilidade suficiente para fazer curvas no interior do filtro durante a operação de filtração.

Foi empregado, ainda, um sistema para possibilitar a condução do bocal para o exterior da unidade filtrante, em caso de eventuais operações de desobstrução/manutenção, uma vez que essa atividade fica impossibilitada com o dispositivo no interior do filtro. A suspensão do bocal foi realizada por um cabo de aço fixado à mesma, o qual foi preso na borda superior do filtro enquanto o mesmo opera no modo filtração ou lavagem. Assim, a crepina permanece na sua correta profundidade em relação à camada filtrante, devido ao comprimento especificado do cabo, que é flexível, porém inelástico.

O içamento da peça serve para casos em que o nível dos piezômetros estejam acima do esperado e a vazão de saída do filtrado esteja consideravelmente abaixo de 13,64 L/min, indicando a obstrução do sistema de drenagem do filtrado, em que se procede como segue:

- Interrompe-se a operação do filtro, deixando de introduzir água não filtrada na unidade e injeta-se água de lavagem no fluxo ascendente, fluidificando o leito filtrante;

- O bocal é içado até o topo do filtro, estando o meio fluidificado, de forma que a peça não seja submetida a maiores esforços, preservando a integridade da mesma;

- Desliga-se a injeção de água de lavagem e realiza-se a limpeza/manutenção do dispositivo, registrando as prováveis causas da colmatação e como se procedeu para a resolução do problema;

- Remonta-se o bocal, então desobstruído, junto à mangueira corrugada de PVC; 
- Injeta-se novamente água de lavagem no fluxo ascendente de modo a fluidificar o leito filtrante e, enquanto isso, coloca-se o bocal novamente na sua posição, no interior da camada filtrante;

- Encerra-se a fluidificação do leito filtrante e espera-se que o mesmo se assente na sua devida posição para, então, continuar a carreira de filtração ou iniciar a seguinte, a depender da limpeza do leito filtrante.

Para a medição da perda de carga ao longo do leito filtrante, foram implantados piezômetros por meio de mangueiras de nível de material plástico transparente. A posição dos piezômetros pode ser visualizada na Fig. 2.

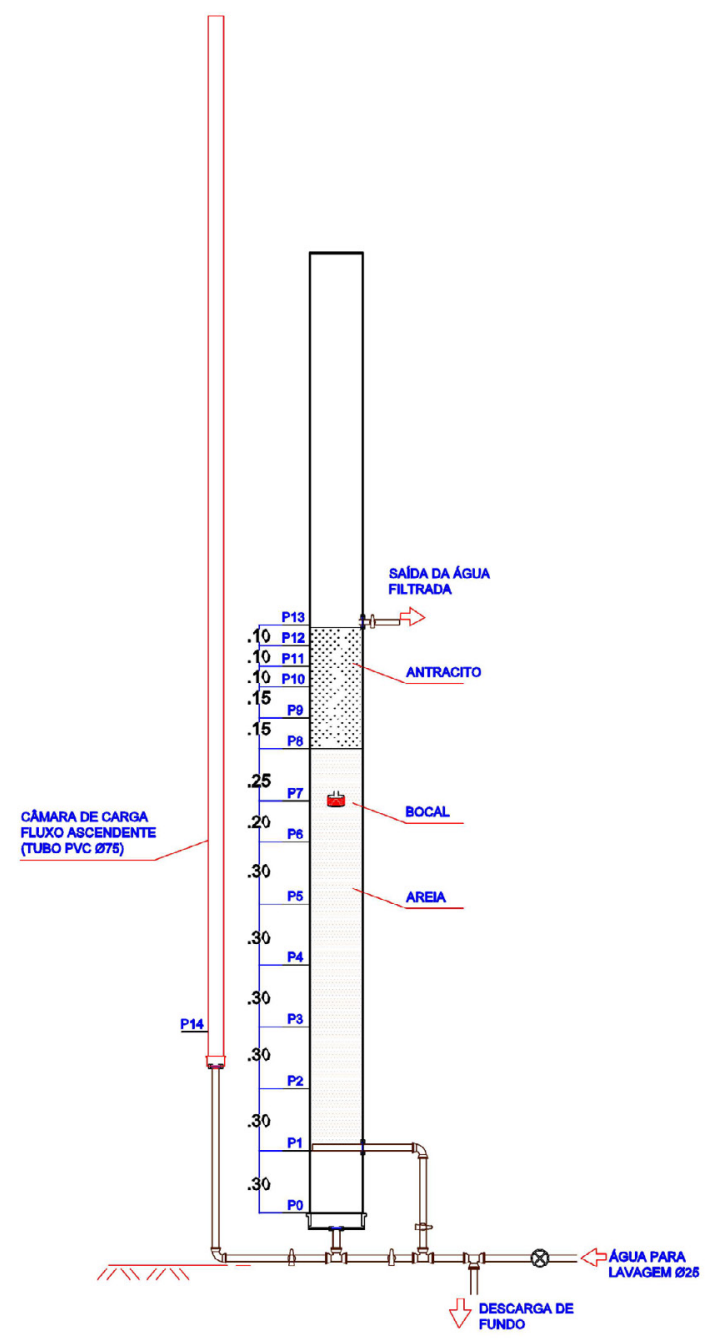

Figura 2 - Filtro piloto com a posição dos piezômetros. Fonte: o autor
Para a retrolavagem, a velocidade ascensional mais adequada obtida e utilizada ao longo desse estudo foi $0,77 \mathrm{~m} / \mathrm{min}$, ou $46 \mathrm{~m}^{3} / \mathrm{m}^{2}$.h. Essa taxa é ligeiramente inferior à faixa recomendada por Hamann e Mckinney (1968) e Vignesan et al. (1983) para lavagem de filtros bifluxos, 47,5 a 55 $\mathrm{m}^{3} / \mathrm{m}^{2}$.h, porém a expansão de todos os materiais ficou acima de $20 \%$, conforme é recomendado para lavagem de filtros.

Para a análise da qualidade da água, o parâmetro analisado foi turbidez. Além de se analisar a água filtrada para fins qualitativos, a turbidez também foi considerada na avaliação quantitativa do filtro: na determinação do tempo de lavagem e na indicação do tempo de recuperação do filtro.

Previamente ao início de cada carreira de filtração foram coletadas amostras da água bruta. Durante os 30 minutos iniciais de cada carreira de filtração, foram coletadas amostras de água filtrada de dois em dois minutos, para o estudo do tempo de recuperação do filtro, item essencial na avaliação da produção efetiva do filtro. Após esse tempo, a água filtrada foi amostrada em intervalos de 30 minutos.

Em todas as operações de retrolavagem do filtro, a cada 30 segundos foi coletada uma amostra da água de lavagem para análise de turbidez, a fim de verificar a adequabilidade do tempo de lavagem determinado em projeto.

As amostras para análise de turbidez durante a injeção de água na interface junto à descarga de fundo foram coletadas no meio dessa operação, ou seja, próximo dos 12,5 segundos após o seu início. 0 mesmo procedimento foi realizado ao final da operação, próximo dos 25 segundos, pouco antes de encerrar essa operação.

\section{RESULTADOS E DISCUSSÕES}

Os resultados da pesquisa são avaliados observando-se os seguintes critérios: capacidade de filtração, produção efetiva, grau de profundida- 
de da filtração, qualidade da água (turbidez) e análise dos critérios de projeto adotados.

\subsection{Capacidade de Filtração}

Devido à qualidade da água bruta (elevada concentração de fitoplâncton), a duração média das dez carreiras analisadas foi baixa, igual a $3,00 \pm 0,20 \mathrm{~h}$. Deve ser considerado que a carga hi- dráulica máxima aplicada à parte de escoamento descendente foi menor ao geralmente empregado em estações de tratamento em escala real. Todas as carreiras de filtração foram encerradas devido à carga hidráulica disponível para o fluxo descendente. A Fig. 3 ilustra a evolução média da perda de carga ao longo da carreira de filtração no fluxo descendente e no ascendente.

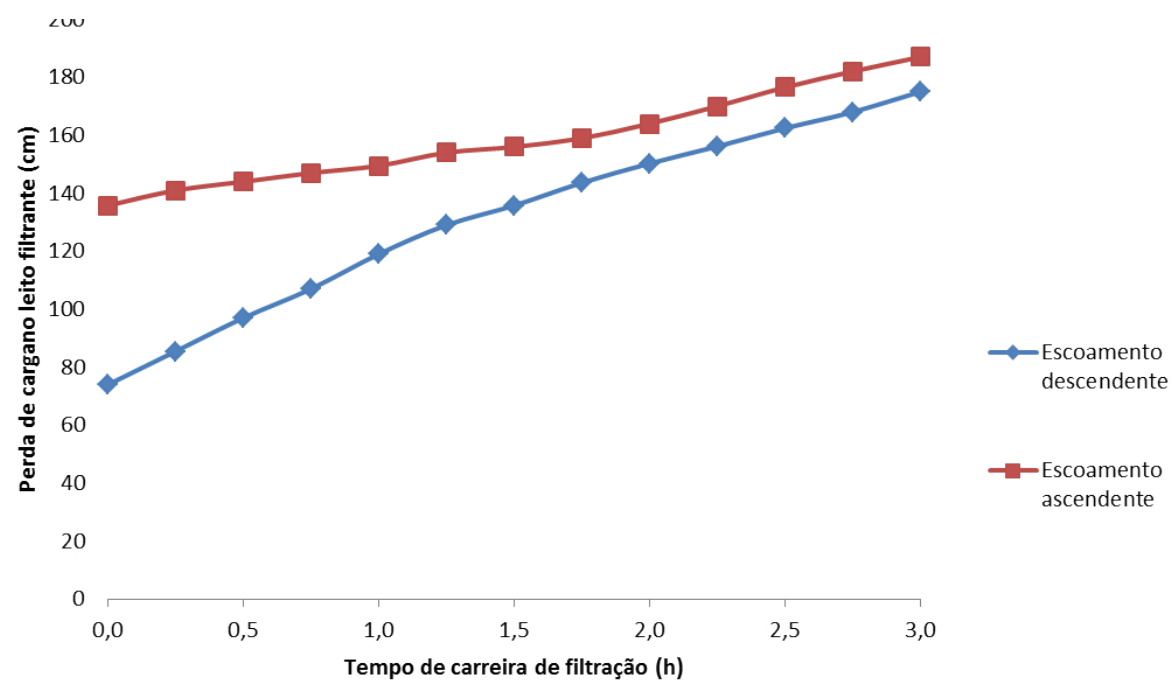

Figura 3 - Comportamento médio das perdas de carga no meio filtrante no escoamento descendente e ascendente durante a carreira de filtração.

A elevação acentuada da perda de carga no meio filtrante, especialmente no fluxo descendente, está associada ao fato de que a água da Lagoa do Peri não é adequada para a tecnologia por filtração direta. A grande quantidade de cianobactérias presentes na lagoa do Peri faz com que a penetração (filtração em profundidade) seja baixa, aspecto mais impactante no fluxo descendente. Enquanto no fluxo descendente a perda de carga variou 1,0 $\mathrm{m}$ até o encerramento das carreiras, no ascendente variou apenas $54 \mathrm{~cm}$, em média. Esse fato está associado ao fato de que no fluxo ascendente a água passa por grãos cada vez menores ao longo do leito filtrante.

Todas as carreiras de filtração foram encerradas devido ao consumo da carga hidráulica do fluxo descendente. Não houve transpasse, conforme demonstrado na Fig. 4.

Com o objetivo de obter uma estimativa da duração da carreira de filtração para o caso de se possuir uma carga hidráulica disponível de $2,0 \mathrm{~m}$, mantendo-se os demais critérios de operação, como a taxa de filtração, foram determinadas as linhas de tendências de avanço da perda de carga ao longo do tempo. No fluxo descendente, a perda de carga no meio filtrante se elevou em média 33,8 $\mathrm{cm}$ a cada hora de carreira de filtração; já no ascendente esse valor foi de 20,07. Assumindo-se a mesma tendência de avanço da perda de carga em cada um dos fluxos do filtro e que não se atingisse o transpasse no decorrer desse período, uma carga hidráulica disponível de 2,0 m no fluxo descenden- 
te seria atingida após 5,92 h, ou 5h55min. Para a porção ascendente, isso ocorreria após $9,97 \mathrm{~h}$, ou seja, 9h58min. Dessa forma, a carreira seria encer- rada após cerca de 6,00 h para o caso de haver 2,0 m de carga hidráulica disponível, ou seja, descontada a carga inicial, referente ao filtro limpo.

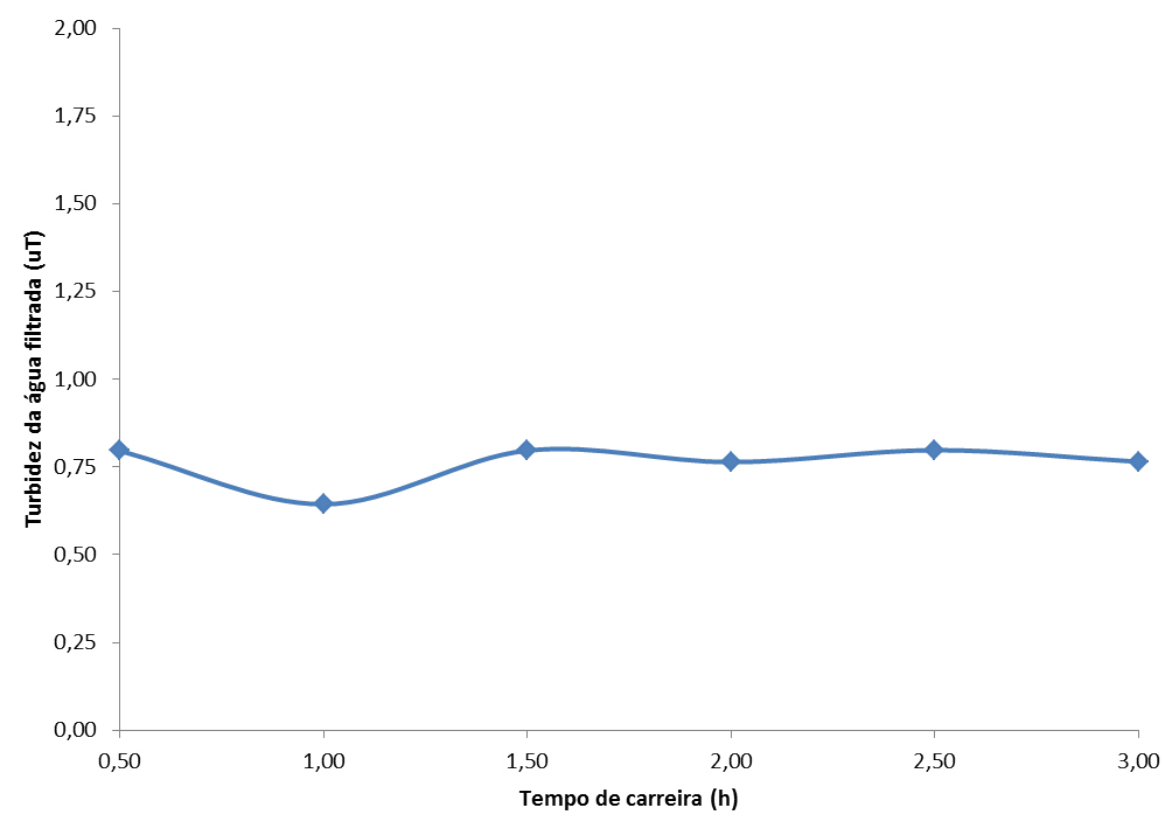

Figura 4 - Resultados médios da turbidez (UT) ao longo da carreira de filtração.

Seguindo-se o mesmo raciocínio, para ocorrer o consumo da carga hidráulica de ambos os fluxos ao mesmo tempo, o fluxo descendente deveria dispor de uma carga hidráulica disponível $68 \%$ maior do que a do fluxo ascendente.

Carreiras de filtração com duração próxima à obtida pela extrapolação dos resultados do presente estudo, qual seja $6,4+0,8 \mathrm{~h}$, foram obtidas por Dalsasso (2005), com utilização de água bruta proveniente do mesmo manancial.

\subsection{Produção Efetiva}

Para a determinação da produção efetiva do filtro foram considerados os dados práticos das seguintes etapas: recuperação do filtro, filtração, descarga de fundo na interface e retrolavagem. Os valores médios de turbidez no período de recuperação, conforme a Fig. 5, indicam que o tempo de recuperação foi de 8 minutos.

Como não houve casos entre as carreiras de filtração analisadas em que a carga hidráulica disponível no fluxo ascendente foi consumida anteriormente à do fluxo descendente, a descarga de fundo com injeção na interface foi realizada apenas anteriormente a cada retrolavagem. Essas operações duraram $25 \mathrm{~s}$ e utilizaram uma taxa de $51 \mathrm{~m}^{3} / \mathrm{m}^{2} . \mathrm{d}$.

A vazão de retrolavagem praticada foi $37,5 \mathrm{~L} /$ min, a mais próxima a $41,0 \mathrm{~L} / \mathrm{s}$ prevista em projeto que não promoveu o arraste de material filtrante. Essa vazão utilizada corresponde a uma velocidade ascensional de $0,77 \mathrm{~m} / \mathrm{min}$, ou a uma taxa de $46 \mathrm{~m}^{3} / \mathrm{m}^{2}$.h. Essa taxa é ligeiramente inferior à faixa recomendada por Hamann e Mckinney (1968) e Vignesan et al. (1983) para lavagem de filtros bifluxos, 47,5 a $55 \mathrm{~m}^{3} / \mathrm{m}^{2}$.h. 


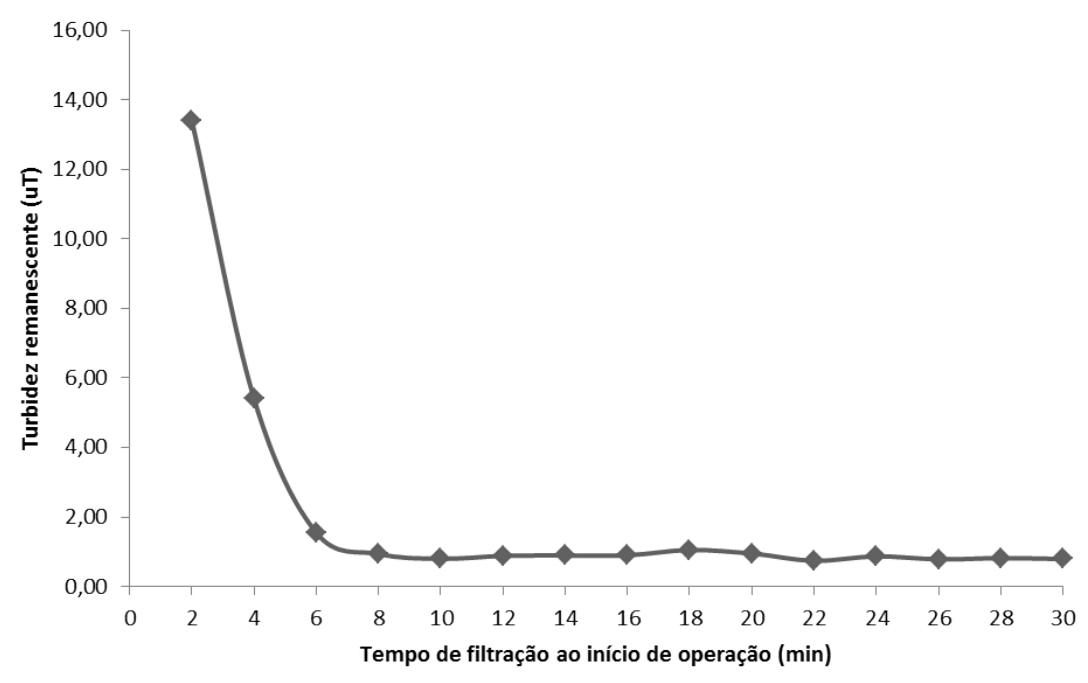

Figura 5 - Média da turbidez no período de recuperação de dez carreiras de filtração.

Com o emprego da vazão de 37,5 L/min, a água de retrolavagem necessita de aproximadamente $1 \mathrm{~min} 30$ s para chegar ao ponto de amostragem, que fica na parte inferior da sala do piloto. A turbidez estabiliza em um valor adequado (abaixo de 20 uT) entre a coleta correspondente ao tem- po de $10 \mathrm{~min} 30 \mathrm{~s}$ e o de $11 \mathrm{~min}$. Dessa forma, fixou-se o período de lavagem em 12 min30s.

Os resultados de turbidez durante a retrolavagem são apresentados na Fig. 6. O volume total de água consumido na operação do filtro para a retrolavagem foi igual a $470 \mathrm{~L}$.

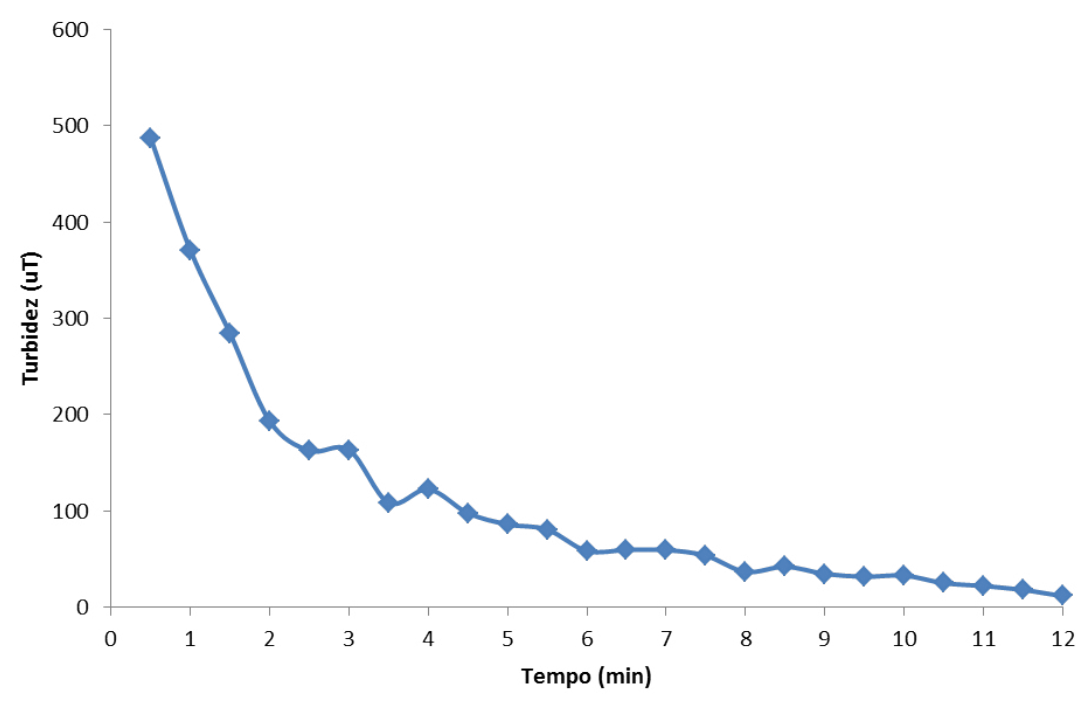

Figura 6 - Curva de turbidez obtida durante a retrolavagem do filtro de dupla camada de antracito e areia (valores médios padrão de uma amostra de dez carreiras).

Com as informações da operação conforme anteriormente abordadas, procedeu-se com a definição da produção efetiva, conforme Tabela 3. 
Tabela 3 - Produção efetiva do filtro rápido bifluxo, valores médios obtidos com a análise de dez carreiras de filtração.

\begin{tabular}{|c|c|c|c|c|c|}
\hline $\mathrm{tF}(\mathrm{h})$ & 3 & $\mathrm{VF}(\mathrm{m} / \mathrm{h})$ & 16,67 & $\operatorname{UVCF}\left(\mathrm{m}^{3} / \mathrm{m}^{2}\right)$ & 50 \\
\hline $\mathrm{tR}(\mathrm{h})$ & 0,215 & VR (m/h) & 46,2 & $\operatorname{UVR}\left(\mathrm{m}^{3} / \mathrm{m}^{2}\right)$ & 9,93 \\
\hline $\mathrm{tRec}(\mathrm{h})$ & 0,133 & $\begin{array}{c}\text { Velocidade da } \\
\text { recuperação }=\text { VF }(\mathrm{m} / \mathrm{h})\end{array}$ & 16,67 & Uvrec $\left(\mathrm{m}^{3} / \mathrm{m}^{2}\right)$ & 2,22 \\
\hline$t D$ & 0,007 & $\mathrm{VD}(\mathrm{m} / \mathrm{h})$ & 51 & UVD & 0,35 \\
\hline
\end{tabular}

Sendo: VF é a velocidade de filtração, $m / h$; VR é a velocidade de retrolavagem, $m / h$; VD é a velocidade na operação da $D F I, m / h ;$ tF é a duração da carreira de filtração, h; tR é o tempo de retrolavagem, h; tRec é o tempo de recuperação, h; td é o tempo de descarga de fundo com injeção na interface, h; UVCF é o volume durante a carreira; UVR é o volume de retrolavagem do filtro; UVD é o volume de descarga de fundo com injeção na interface; UVRec é o volume utilizado no período de recuperação.

Claramente, uma produção efetiva como a obtida está bem abaixo da ideal, que é de $95 \%$. Porém a carga hidráulica disponível para ambos os fluxos do filtro bifluxo do experimento foi menor do que a empregada em ETAs que, de forma geral, é em torno de 2,0 $\mathrm{m}$.

Extrapolando-se a curva da evolução da perda de carga ao longo da carreira de filtração, as- sumindo-se a mesma tendência de evolução da mesma obtida experimentalmente e para o caso de não haver transpasse, pode-se estimar a duração da carreira para o caso de se dispor de 2,0 m de carga hidráulica, obtendo-se que a carreira duraria $6,0 \mathrm{~h}$. A Tabela 4 demonstra a produção efetiva com essa extrapolação:

Tabela 4 - Produção efetiva do filtro rápido bifluxo, valores obtidos a partir da extrapolação da linha de tendência de evolução da perda de carga no meio filtrante, considerando uma carga hidráulica disponível de 2,0 m.

(O significado das siglas segue o exposto na Tabela 3).

\begin{tabular}{|c|c|c|c|c|c|}
\hline tF (h) & 6,0 & $\mathrm{VF}(\mathrm{m} / \mathrm{h})$ & 16,67 & UVCF $\left(\mathrm{m}^{3} / \mathrm{m}^{2}\right)$ & 100,02 \\
\hline $\mathrm{tR}(\mathrm{h})$ & 0,215 & $\mathrm{VR}(\mathrm{m} / \mathrm{h})$ & 46,2 & $\mathrm{UVR}\left(\mathrm{m}^{3} / \mathrm{m}^{2}\right)$ & 9,93 \\
\hline tRec (h) & 0,133 & $\begin{array}{c}\text { Velocidade da } \\
\text { recuperação }=\mathrm{VF}(\mathrm{m} / \mathrm{h})\end{array}$ & 16,67 & UVrec $\left(\mathrm{m}^{3} / \mathrm{m}^{2}\right)$ & 2,22 \\
\hline tD & 0,007 & $\mathrm{VD}(\mathrm{m} / \mathrm{h})$ & 51 & $\mathrm{UVD}$ & 0,35 \\
\hline Produção Efetiva (\%) 87,52 & & & \\
\hline
\end{tabular}

Mantendo-se o demais tempos e taxas, a carreira de filtração deveria durar 15,0 h para se obter uma produção efetiva de 95\%. Uma das possibilidades para atingir essa duração de carreira seria realizar o tratamento por ciclo completo, adicionando etapa de floculação e decantação (ou flotação). Dalsasso (2005), com utilização de água bruta proveniente do mesmo manancial, obteve carreiras com duração $68 \%$ maior com testes de aplicação de pré-floculação. Já Mondardo \& Melo Filho (2003) aplicaram préozonização (1,0 mg 03/L) para então proceder com a filtração direta, em que foi demonstrado obter carreiras até $50 \%$ mais longas.

\subsection{Grau de Profundidade da Filtração}

A profundidade máxima do leito filtrante no escoamento descendente que efetivamente reteve impurezas corresponde ao ponto em que as curvas da Fig. 7 passam a ser paralelas.

Observa-se que, mesmo com dois materiais filtrantes, o antracito e a areia, com granulometrias consideravelmente distintas, a penetração (filtração em profundidade) foi baixa, em torno de $45 \mathrm{~cm}$. Na realidade, com base nesse resultado, pode-se dizer que a areia praticamente não reteve impurezas no fluxo descendente. Com esse resultado, mantidos os demais critérios de projeto e a água bruta utilizada, indica-se que a profundidade do leito filtrante no fluxo descendente pode ser reduzida. 


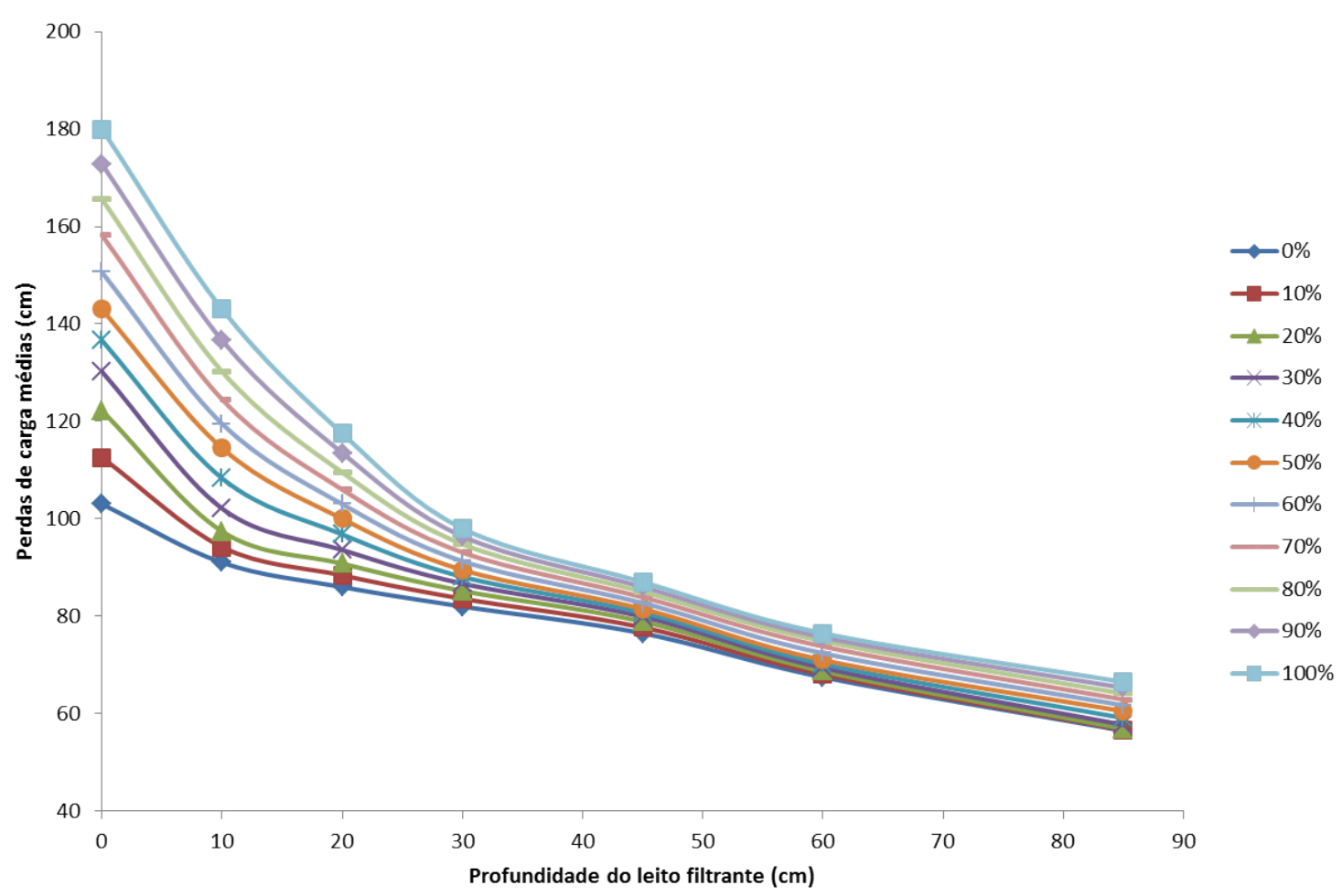

Figura 7 - Ação da profundidade no filtro, em sua porção descendente (a porcentagem é em relação à duração da carreira de filtração)

Schontag (2015) utilizou água bruta do mesmo manancial em filtração direta descendente, com dupla camada filtrante. A penetração de impurezas, apesar de maior do que a do presente estudo, também não chegou à camada de areia, resultado associado à presença de concentrações elevadas de fitoplâncton.

A porção ascendente do filtro do presente estudo, mesmo com uma perda de carga no meio filtrante com evolução mais lenta, também não demonstrou uma elevada penetração das impurezas, como pode ser visto na Fig. 8.

Percebe-se que as impurezas foram retidas praticamente na camada suporte e na primeira sub- camada de $30 \mathrm{~cm}$ de areia, de baixo pra cima. Com esse resultado, mantidos os demais critérios de projeto e a água bruta utilizada, indica-se que a profundidade do leito filtrante no fluxo ascendente pode ser reduzida.

Uma análise do potencial de prolongamento da carreira de filtração devido à aplicação de DFls no presente estudo não foi realizada pois todas as carreiras de filtração realizadas foram interrompidas devido ao consumo da carga hidráulica disponível no fluxo descendente. Dessa forma, não foram realizadas descargas de fundo intermediárias (durante a carreira de filtração) com injeção de água na interface e sim apenas previamente à retrolavagem. 


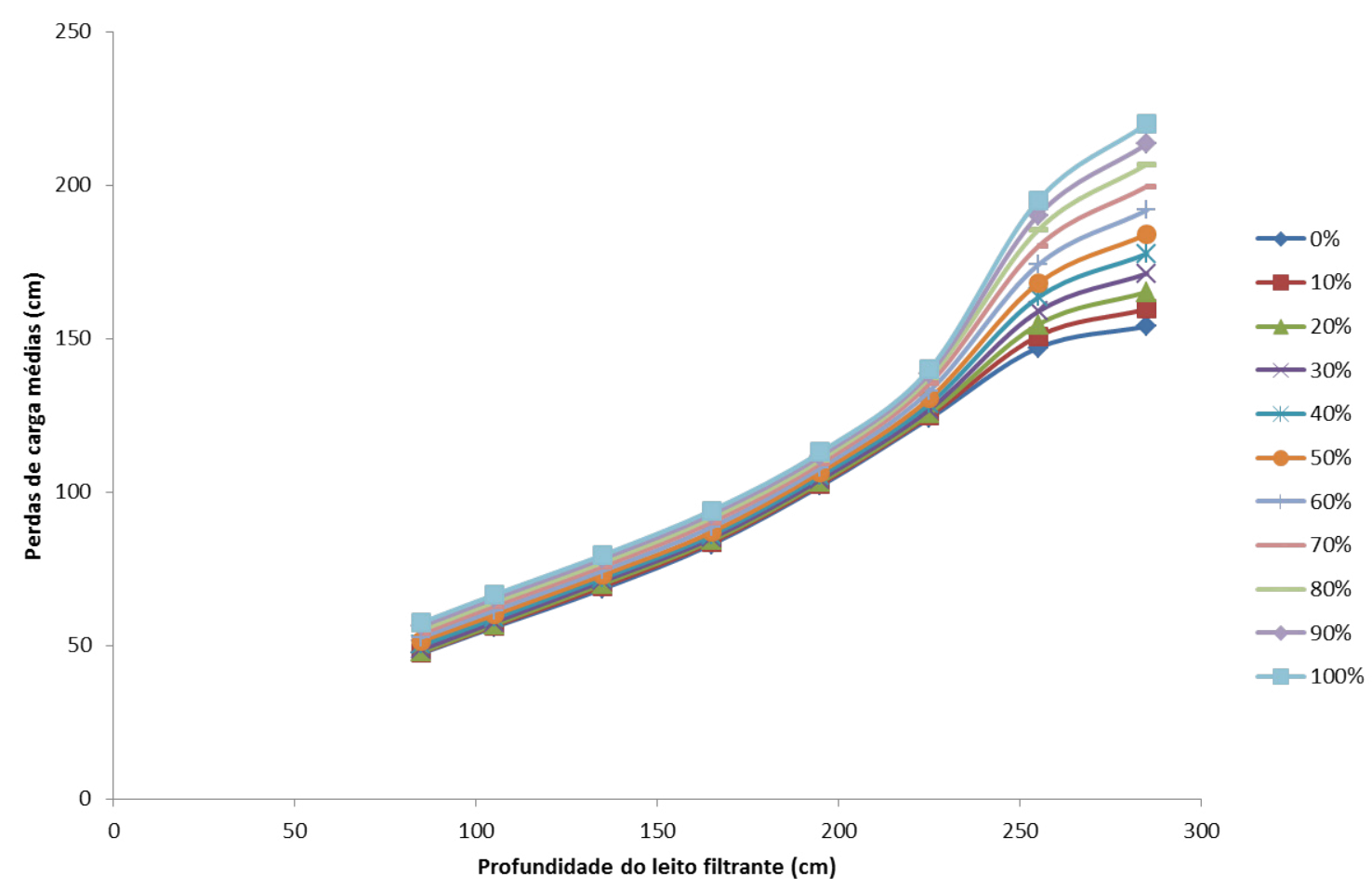

Figura 8 - Ação da profundidade no filtro, em sua parcela ascendente (a porcentagem é em relação à duração da carreira de filtração).

\subsection{Qualidade da Água (Turbidez)}

A turbidez da água filtrada foi verificada, com exceção do período de recuperação, a cada 30 min. Aágua bruta também foi analisada previamente a cada carreira de filtração. Os valores médios e seus desvios-padrão médios são apresentados na Tabela 5.

Tabela 5 - Valores médios e desvios-padrão médios dos resultados de turbidez da água bruta e filtrada, para as 10 carreiras.

\begin{tabular}{|c|c|c|}
\hline Tempo (h) & Turbidez média & Desvio padrão \\
\hline (Água bruta) & 9,47 & 1,42 \\
\hline 0,50 & 0,80 & 0,57 \\
\hline 1,00 & 0,82 & 0,62 \\
\hline 1,50 & 0,94 & 0,42 \\
\hline 2,00 & 0,90 & 0,45 \\
\hline 2,50 & 0,91 & 0,51 \\
\hline 3,00 & 1,05 & 0,43 \\
\hline
\end{tabular}

Como pode ser observado na Tabela 5, o resultado da qualidade da água filtrada não é ideal e não atende ao preconizado pela Portaria de Consolidação No 05 do Ministério da Saúde (BRASIL, 2017) para água filtrada por filtração rápida, a qual deve possuir uma turbidez máxima de 0,5 uT em no mínimo $95 \%$ das amostras. A dificuldade no atendimento desse parâmetro, mesmo com uma turbidez relativamente baixa da água bruta, ocorre visto que a tecnologia de filtração direta não é a recomendada para a água bruta com as características apresentadas pelo manancial da Lagoa do Peri. Essa tecnologia foi escolhida em função dos índices de turbidez e cor verdadeira do manancial serem baixos, ou seja, inferiores a 10 uT e 20 uH (DALSASSO; SENS, 2006). Entretanto, a elevação da presença de fitoplânctons no manancial, com domínio de espécies filamentosas como a Cylindrospermopsis raciborski e Pseudoanabaena sp, prejudicaram a qualidade da água produzida pelos filtros rápidos diretos. Outros trabalhos já se depararam com esse problema, como os de Mondardo (2009) e Schontag (2015). Todavia, a qualidade da água, nesse caso, não invalida os resultados e a análise do filtro rápido bifluxo, objeto do presente estudo. 


\section{ANÁLISE DOS CRITÉRIOS DE}

\section{PROJETO ADOTADOS}

Todo o sistema de drenagem da água filtrada, desde a crepina até a tubulação externa ao filtro, mostrou-se adequado para a vazão de operação da unidade.

Entretanto, após 42 horas de filtração (14 carreiras), o sistema passou a não exercer a completa drenagem da água filtrada, sendo verificados os seguintes fatos:

- Piezômetro P7 com leitura inicial acima da média de operação. O P7, assim como os outros pie- zômetros, teve sua leitura em rápida ascensão ao longo da carreira em que ocorreu o fato;

- A vazão de saída do filtrado, visível no lado externo do filtro, foi consideravelmente menor do que a normal desde o início da carreira.

Após essa constatação, a carreira de filtração foi interrompida e iniciou-se a operação de retrolavagem, de forma a expandir o meio filtrante e possibilitar o içamento da crepina para sua verificação e limpeza. Com o dispositivo içado até o exterior do corpo do filtro, foi confirmada visualmente a sua colmatação (Fig. 9), em que se desmontou o mesmo e se procedeu com a sua limpeza/desobstrução.
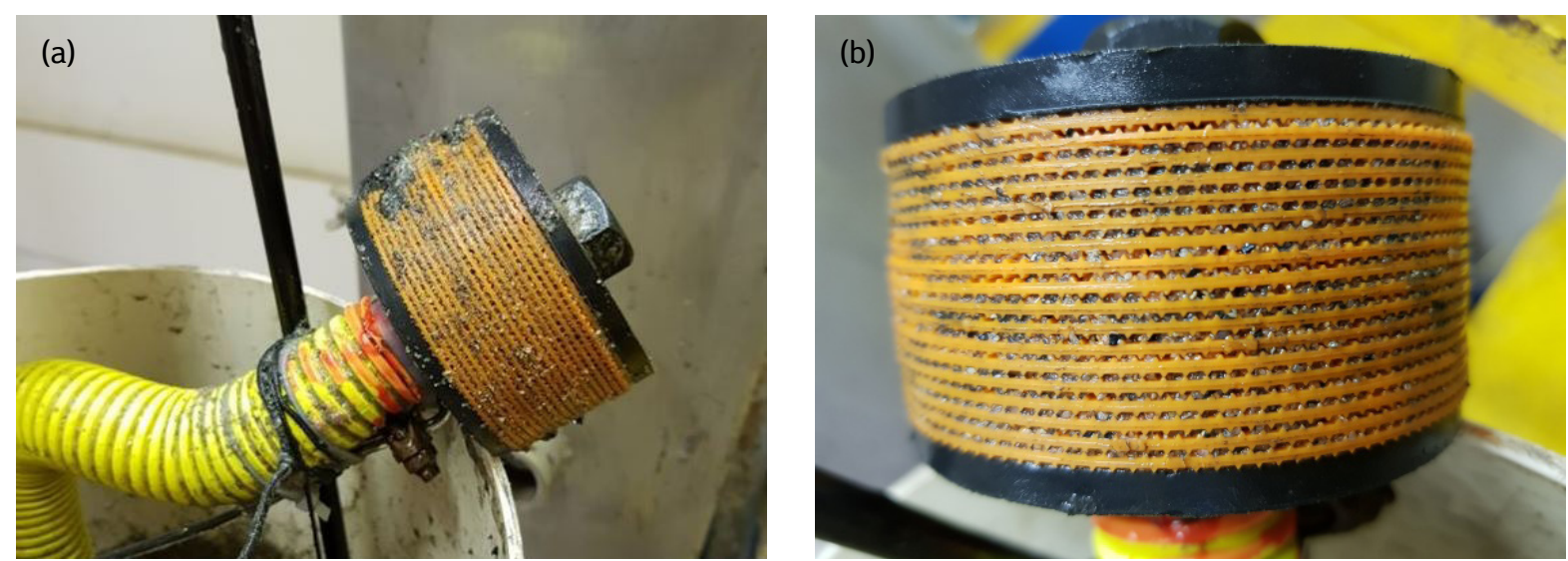

Figura 9 - a) Aspecto do bocal obstruído e içado; b) Detalhe das aberturas entre os discos, obstruídas por material filtrante Fonte: $o$ autor.

A limpeza se deu da seguinte forma:

- a parte inferior da crepina, que é fixada à mangueira, foi a única parte do dispositivo lavada no local (topo do filtro), com água, conforme a Fig. 10.

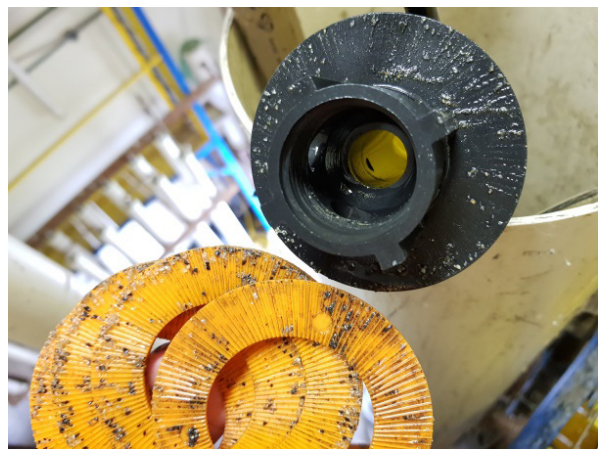

Figura 10: Desmontagem do bocal obstruído para sua limpeza

Fonte: o autor 
- Os discos encaixados e a parte superior da crepina foram conduzidos ao laboratório e lavados com água. Os sulcos da peça possuem orientação radial, sendo suas aberturas voltadas ao experior da crepina maiores do que as voltadas ao eixo da mesma (Fig. 11).

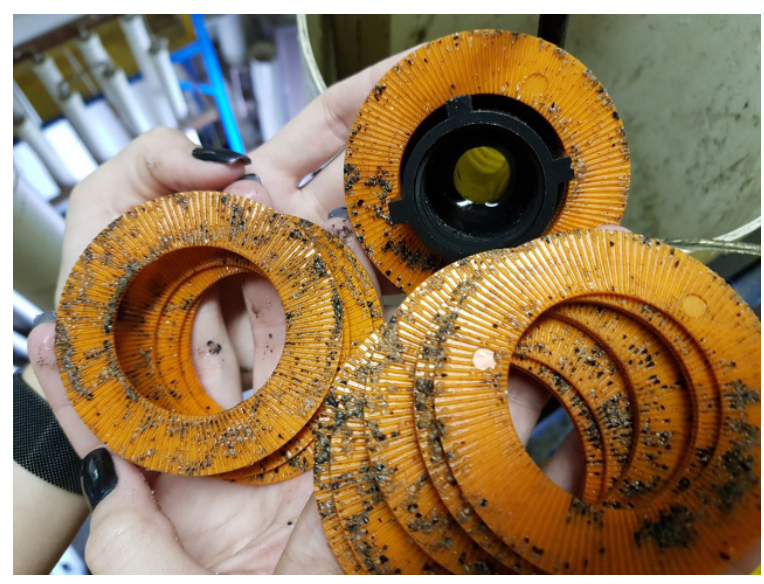

Figura 11: Detalhe das passagens entre os discos, obstruídas por material filtrante Fonte: o autor.

Os materiais depositados nas três partes principais de crepina, após serem retirados com água, foram armazenados em um béquer para observação visual de sua composição (Fig. 12). Foram observados grãos de areia e de carvão antracito, este último em menor quantidade.

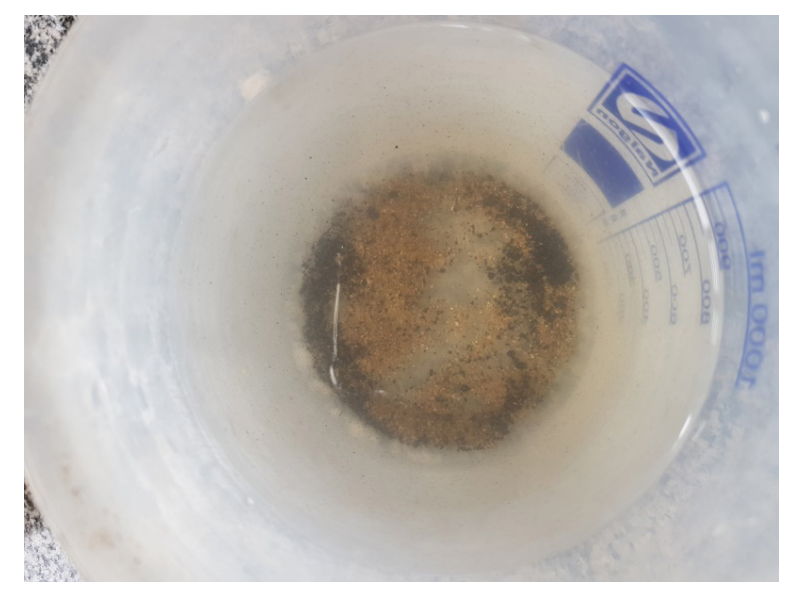

Figura 12 - Análise visual dos materiais retidos nas aberturas do bocal

Fonte: o autor.
Essa obstrução pode ser explicada pelo diâmetro mínimo da areia e do carvão antracito, de acordo com sua análise granulométrica, ser menor que $0,40 \mathrm{~mm}$, que é aproximadamente a abertura dos sulcos entre os discos da crepina, de acordo com o fabricante. Uma forma de prevenir essa obstrução da crepina e parada na operação do filtro seria a determinação, além do diâmetro efetivo dos materiais filtrantes, também fixar o diâmetro mínimo dos mesmos, sendo um valor maior que $0,40 \mathrm{~mm}$.

\subsection{Descarga de fundo com injeção na interface}

A turbidez média das amostras coletadas ao meio da descarga de fundo com injeção de água na interface foi igual a $168,1+44,4 \mathrm{uT}$, e ao final da mesma foi de 3,6+1,4.

O resultado ao início da operação é compatível com os de turbidez aos primeiros minutos da operação de retrolavagem, o que confirma a efetividade da camada suporte na retenção de impurezas. A eficiência da realização da descarga de fundo com injeção de água na interface na limpeza da porção inferior do filtro bifluxo é corroborada pela baixa turbidez ao final da mesma, assim como a recuperação da perda de carga inicial no leito filtrante.

\subsection{Camadas e materiais filtrantes}

A profundidade elevada do leito filtrante implicou em um piloto bastante alto e em um tempo de lavagem (12min30s) maior do que o geralmente empregado em filtros de fluxo único, o que implica negativamente na produção efetiva.

Mesmo com o emprego de dupla camada filtrante no fluxo descendente, as impurezas foram efetivamente retidas apenas em uma porção da camada de antracito. $\mathrm{Na}$ porção do filtro com fluxo ascendente o grau de profundidade da filtração foi baixo. 
Um aspecto importante relativo à granulometria dos materiais filtrantes é a especificação do diâmetro mínimo dos mesmos, dada a abertura dos canais do bocal utilizado para a coleta do filtrado do filtro bifluxo. Esse diâmetro seria de $0,40 \mathrm{~mm}$ para o bocal empregado neste estudo.

\section{CONCLUSÃO}

Com os resultados obtidos durante o estudo, foi possível tecer as seguintes conclusões:

- A duração média das carreiras de filtração foi consideravelmente curta. Mesmo com a extrapolação da linha de tendência da evolução da perda de carga em cada um dos fluxos de filtração, para uma carga hidráulica disponível de 2,00 m para cada porção do filtro, a carreira de filtração duraria cerca de 6,0 h.;

- O grau de profundidade da filtração foi reduzido para ambos os fluxos de filtração, ficando em torno de $45 \mathrm{~cm}$ para a porção de fluxo descendente, isto é, não chegou à camada de areia. $\mathrm{Na}$ porção de fluxo ascendente, a frente de impurezas incluiu a camada suporte e a primeira subcamada de areia de baixo para cima, de $30 \mathrm{~cm}$ de espessura, totalizando uma profundidade de 60 $\mathrm{cm}$ de meio granular;

- Como esperado, a colmatação ocorreu primeiramente no filtro de fluxo descendente, em que a água flui entre grãos cada vez maiores. Não foram realizadas descargas de fundo intermediárias com injeção de água na interface durante as carreiras, e sim apenas previamente à retrolavagem. Os resultados de turbidez e o restabelecimento da perda de carga das duas porções do leito filtrante demonstraram a efetividade das descargas de fundo com injeção na interface e das retrolavagens realizadas;

- A produção efetiva, de acordo com os resultados obtidos experimentalmente, ficou em $75 \%$. Com uma duração de $6,0 \mathrm{~h}$ de carreira de fil- tração, seria atingida uma produção efetiva de $87,3 \%$;

- A turbidez da água filtrada se estabilizou a partir de 8 min de carreira e teve um valor médio de 0,90 uT, representando uma remoção média de $90 \%$ em relação à água bruta. Os resultados de turbidez da água filtrada não são ideais e não atendem à legislação aplicável;

- Ao longo do estudo, após 42 h totais de filtração, o bocal desmontável sofreu obstrução, implicando na interrupção da então carreira de filtração e na limpeza do dispositivo. A limpeza realizada se mostrou eficiente, não voltando a ocorrer essa colmatação até o encerramento dos experimentos. Concluiu-se que o fato determinante para a obstrução do bocal foi o emprego de materiais filtrantes com diâmetros mínimos menores do que a abertura dos sulcos formados pelos discos do dispositivo;

- De fato, os critérios de projeto de filtros rápidos bifluxos precisam ser melhor compreendidos para o seu uso em escala real.

\section{CONTRIBUIÇÃO DOS AUTORES}

Todos os autores contribuíram de forma igualitária.

\section{REFERÊNCIAS}

BAYLIS, J. R. Variable rate filtration. Pure Water, v. XI, n. 5, p. 86114, May 1959.

BRASIL. Ministério da Saúde. Portaria de Consolidação No 05, de 28 de setembro de 2017. Brasília, DF, 2011.

CRITTENDEN, J. .; TRUSSELL, R. .; HAND, D. .; HOWE, K. .; TCHOBANOGLOUS, G. Water Treatment Principles and Design. $2^{\circ}$. ed. Hoboken, NJ: John Wile \& Sons, 2011. p. 880-932.

DALSASSO, R. L. Floculação em meio Granular, Descendente no Tratamento de Água para Abastecimento. Tese (Doutorado em Engenharia Ambiental), UFSC: Florianópolis/SC, 2005. p.254. https://doi.org/10.1590/S1413-41522006000300007

DALSASSO, R. L.; SENS, M. L. Filtração direta com pré-floculação e coagulação com sulfato de alumínio e hidroxicloreto de alumínio: 
estudo com água de manancial eutrofizado. Eng. sanit. ambient., v. 11, n. 3, p. 241-249, 2006.

DI BERNARDO, L.; FERNANDES, L. C. Estudos sobre as influências da composição da camada suporte e do método de realização de descargas de fundo intermediárias do desempenho de sistemas de filtração direta ascendente. In: Congresso brasileiro de engenharia sanitária e ambiental, 14., São Paulo, set. 1987. p. 83106. Anais...

DI BERNARDO, L. (1993). Métodos e técnicas de tratamento de água. Rio de Janeiro, ABES.

DI BERNARDO, L.; DANTAS, A. D. Métodos e técnicas de tratamento de água. 2. Ed. São Carlos: Rima, 2005. 1656 p. 2 v.

Di Bernardo L, Di Bernardo A, Centurione Filho PL. Ensaios de tratabilidade de água e dos resíduos gerados em estações de tratamento de água. São Carlos: RIMA; 2002.

DI BERNARDO, L. (Coord.); MENDES, C. G. N.; BRANDÃO, C. C. S.; SENS, M. L. \& PÁDUA, V. L. Tratamento de Água para Abastecimento por Filtração Direta. Rio de Janeiro, ABES, 498p., 2003

HAMANN, C. L.; MCKINNEY, R. E. Upflow filtration process. American Water Works Association, v. 60, p. 1023-1039, 1968. https://doi.org/10.1002/j.1551-8833.1968.tb03640.x
HIDRO SOLO (2019). Maceió, Brasil. Disponível em: <www. hidrosolo.com.br>. Acesso em: 22 junho 2019.

MACINTYRE, Archibald Joseph. Instalações hidráulicas. Rio de Janeiro: Guanabara, 1991.

MONDARDO, R. Avaliação da Filtração em Margem como PréTratamento à Filtração Direta Descendente na remoção de células de Cianobactérias e Saxitoxinas. Tese (Doutorado em Engenharia Ambiental), UFSC: 2009. p. 290.

RICHTER, C. A.; AZEVEDO NETTO, J. M. Tratamento de água: tecnologia atualizada. São Paulo: E. Blücher, 1991.

SCHONTAG, J. M. Esferas de poliestireno como elemento filtrante em filtração rápida descendente. Tese (Doutorado em Engenharia Sanitária e Ambiental), Universidade Federal de Santa Catarina, 2015.

TRUSSELL, R. .; CHANG, M. Review of flow through porous media as a applied to Head loss in water filters. AWWA, v. 125, n. 11, p. 998-1006, 1999. https://doi.org/10.1061/(ASCE)07339372(1999)125:11(998)

VIGNESAN, S.; TAM, D. M.; VISVANATHAN, C.; THANH, N. C.; SCHULZ, C. R. Enviromental sanitation reviews. Water filtration technologies for developing countries. Bangkok: Enviromental Sanitation Information Center, 1983. 110p. 